\title{
THE POSSIBILITIES OF DECREASING THE URBAN HEAT ISLAND
}

\author{
OLÁH, A.B. \\ Corvinus University of Budapest, Department of Garden and Open Space Design \\ 1118 Budapest, Villányi út 29-43., Hungary \\ (phone: +36-30-658-458) \\ e-mail: olah.andras.bela@gmail.com \\ (Received $28^{\text {th }}$ October 2011; accepted $5^{\text {th }}$ January 2012)
}

\begin{abstract}
The urban heat island phenomenon is one of the greatest challenges of the present days regarding the sustainability of our cities and settlements. A great amount of research has already been completed considering the urban heat island, with a significant part of them based on the utilization of remote sensing. The results show that in the case of the densely built-up areas of Hungary the maximal intensity of the urban heat island can be experienced in the industrial areas and in the extremely densely built-up zones, while water bodies and surfaces covered by vegetation proved to be the coolest zones under all circumstances. Thus, according to the results only water and green surfaces are capable of effectively reducing the urban heat island. Firstly, urban green surfaces and water bodies must be created to become capable of decreasing the urban heat island to the maximal extent. Secondly, it is possible to maximize the rate of green and water coverage within settlements only with the tools of urban planning. Thus it is essential in the case of urban planning to implement the existing regulation tools to prevent or minimize the further intensifying of the urban heat island.
\end{abstract}

Keywords: urban heat island, urban climate, climate adaptation, urban green system

\section{Introduction}

In the recent 200 years a heretofore unknown problem has appeared in relation to the liveability of the cities, and by now this relatively young phenomenon has become one of the most important issues (if not the most important one) in the same context. The phenomenon was already recognized almost exactly 200 years ago (Howard, 1818) in a study describing the urban climate of London. Basically this problem has become significant due to the industrialisation and the consequential expansion of the cities happening on an extremely large scale. In fact this problem obviously existed beforehand as well, however, it was not reasonably perceivable in everyday life, or at the most as a positive phenomenon (e.g. the weather in wintertime was less cold).

It has been in the last 50 years that the phenomenon has become really serious, as several factors have added to its intensity and size beside the basic reasons. The greatest additional factor is global warming, which also has rapidly become an increasingly serious factor in the last 50 years. Its impact is very complex, in certain cases it might even happen to decrease the intensity of the urban heat island phenomenon (e.g. if the number of cloudy days increase locally), but in Central Europe and especially in Hungary the two phenomena unluckily intensify each other (Mika, 1999).

The other serious factor is a consequence of motorisation, which led to the extreme expansion of cities even beyond the size of the settlements which formed during the industrial revolution (e.g. London, $19^{\text {th }}$ century). The third phenomenon is the radical growth of the number of inhabitants and the migration of people from the rural regions to the city; consequently besides the geographical expansion of these urban areas the 
intensity of their usage is also increasing. These altogether mediately increase the range and intensity of the urban heat island.

The consequence of the above mentioned factors is that nowadays the urban heat island endangers the urban liveability to a higher extent than the air pollution does, which used to be considered as the most unpleasant component of urban life for several centuries. The heat wave of 2003 in Europe, which only in France resulted more than 14000 deaths in three weeks, clearly showed that global warming, together with other factors increasing the temperature (urban heat island) can have direct radical impacts on everyday life. There has been made also a very detailed study about the distribution, length and intensities of heat waves in Hungary (Révész, 2008).

The essence of the following research is firstly the examination of the structure of the urban heat island, particularly regarding how the different land use types and land covers can modify the urban heat island on the given site. Thermal infrared satellite images (NASA, 1999) were used in undertaking the examination, since these images were the ones that provided sufficient information on the examined area.

The examined area is Budapest, the capital of Hungary. Geographically the city is located in the Pest Basin and is divided into two parts by the River Danube. The western part is mostly hilly, while the eastern part is plain. Due to its location in a basin, smog appears very easily when the macroclimatic conditions are appropriate for it; furthermore due to its protective relief the local climate is basically somewhat warmer than in the surroundings, which unluckily further increases the urban heat island. The dominant direction of the wind is western, north-western.

During the detailed examination first the satellite image database was analysed and on the basis of the results an architectural, open space design and an urban planning proposal and directive system was developed, which in essence recommends such land covers and land use on the newly built-up or transforming areas, that minimizes the rate of the urban heat island and sets a limit to its further spatial extension.

\section{Review of literature}

First of all the book of Probáld (1974) has to be highlighted among the literature related to the topic; this book summarizes the knowledge on the urban climate of Budapest in 1974. No other similar summarizing work has come into existence ever since, thus it is still the only book to provide the most comprehensive overview on the urban climate of Budapest. However, the global climate has changed a lot since 1974, and on the other hand Budapest and its neighbouring settlements have significantly transformed. This transformation is still in process. Finally some new technologies have appeared which enable a much more detailed analysis of meteorological phenomena, thus many more conclusions become available in relation to the coherence of the meteorological processes taking place in the given area.

In relation to the Hungarian urban climate researches in the present days it is very important to mention the work at the University of Szeged and to highlight the name of János Unger. One of his most important results is the synchronizing of thermal measurements performed on the surface and thermal infrared photos taken from aeroplanes, and by combining these measurements a very detailed temperature distribution map was produced of the town of Szeged (Unger, 2009).

The PhD dissertation of Gál (2009) is also very important, which deals with the interaction between the complex urban surface and the urban heat island. In his thesis he 
examines the correlation of the sky view factor (SVF) and the urban heat island in detail. Basically in this work is proven the anticipated result, that the greater is the SVF, the smaller is the Urban Heat Island.

Furthermore we have to mention the article of Szegedi and Gyarmati (2009), in which on one hand the Oke formula (Oke, 1973) is proved through the examples of settlements in the Hajdúság (an East region in Hungary), and on the other hand through the example of the so called 'Great Forest' Park of Debrecen - the phenomenon of the park cool island (PCI) of urban green surfaces was also clearly evinced.

Last but not least the research programs still in progress at the Eötvös Loránd University, Department of Meteorology must also be mentioned. The thesis of Dezső (2009) summarizes the satellite image measurements of Budapest. This can be considered as a very detailed work in the aspect of meteorology, but it does not contain any detailed urban research, nor any recommendations (as basically this was not an aim of this work). Principally it contains a very detailed examination and description of the urban heat island of Budapest in the last decade, displaying the spatial structure and the development of the phenomenon in detail. However, the examination of those satellite images (ASTER) with a spatial resolution fine enough for urban studies (NASA, 1999) is only a minor chapter of this work. The research was previously published in detail by Pongrácz et al. (2007). Another very interesting work of this institute is a long term forecast for the climate change of the Carpathian Basin (Bartholy et al., 2007). Here must be also mentioned the extreme vulnerability of the climate of the whole Carpathian basin, which comes from the climatically border situation of this region (the oceanic, the mediterranean and the continental effect can be all dominant and the balance is very sensitive). The climatic sensitivity of this region is well introduced in another study of this research group (Bartholy et al., 2009).

Considering the international literature the number of relevant studies is much smaller, as in this case the examined area is very specific (Budapest). Nevertheless it is important to note the name and work of Oke and the article about the energy balance of the inner part of Mexico City during the dry period (Oke et al., 1999), which is very important in the case of a city, in which's macroclimate a lot of mediterranean features had appeared in the last decades, and this trend seems to continue in the future.

Another very interesting study was made in Barcelona (Moreno-garcia, 1994), which shows some details about the day and night periodicity of the urban heat island. According to these measurements the temperature maximum was a little bit lower (with about $0.2^{\circ} \mathrm{C}$ ) by day, but the night temperature minimum was remarkably higher (with about $2.9^{\circ} \mathrm{C}$ ). These values are very interesting from our point of view, but it must be taken into consideration that the geographical location, the macroclimate, the relief and the vegetation are all absolutely different in case of Barcelona than in case of Budapest.

Furthermore there exist well known examples for the remote sensing of the urban heat island (Lee, 1993). It was proven in this study that in case of daytime and cloudless weather the structure of the urban heat island is mainly determined by the different albedos of the different surfaces.

From the energetic point of view it is very important to note the radically increasing energy consumption, which is required for air conditioning. According to some estimation it can be cost tens of million US dollars in case of certain North-American cities (Rosenfeld et al., 1997). 


\section{Materials and methods}

As the urban heat island is a very complex phenomenon with several causes, it is very important to measure this symptom as accurately as possible. The measurement would be extremely difficult if traditional temperature measuring methods were used, as this would require an extremely dense measuring network, which would be impossible even in the richest cities of the world. Consequently a database consisting of satellite images produced by the ASTER sensor (NASA, 1999) has become our primary data source. The usage of satellite images is particularly advantageous when considering the fact that this way it becomes possible to obtain information on the entire territory of the city in the same second. This way the spatial structure of the urban heat island and its correlation with the different land covers and land use types can be accurately examined.

The satellite images used in this research are the so called thermal infrared satellite images, which cover the entire territory of Budapest, while their spatial resolution is $90 \mathrm{~m}$ that can be considered relatively accurate, as they enable the examination of even single urban blocks; however, they do not allow accurate analysing on a deeper level than the city blocks. It is very important to note that these temperature data are so called surface kinetic temperature data and not the traditional air temperature data (measured at a level of $2 \mathrm{~m}$ in shade). They are derived from the thermal infrared radiation intensity of the surface. The difference between these two kinds of temperature values is not remarkable in the aspect of this research, only approx. $1-1.5^{\circ} \mathrm{C}$ (Dobi et al. 2009).

The basic method of the measurement was a comparison between the temperature data (the satellite images) and the land use (as it is stated in the regulation plans) together with the detailed surface cover (Google Earth images). Following the layering of these different images the comparison continued by examining the isotherm lines, meaning that all satellite images were transformed into image sequences. Each element of these sequences has an index number, which is a threshold temperature value.

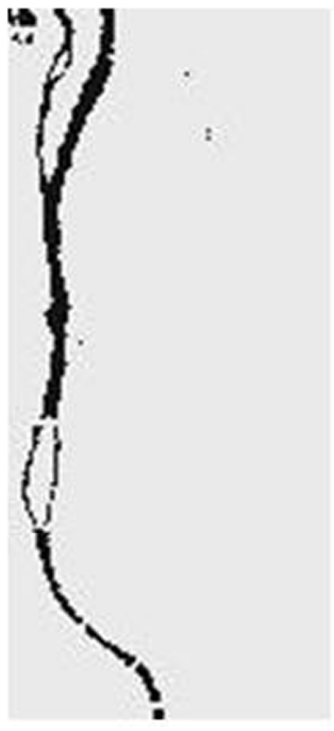

$19{ }^{\circ} \mathrm{C}$

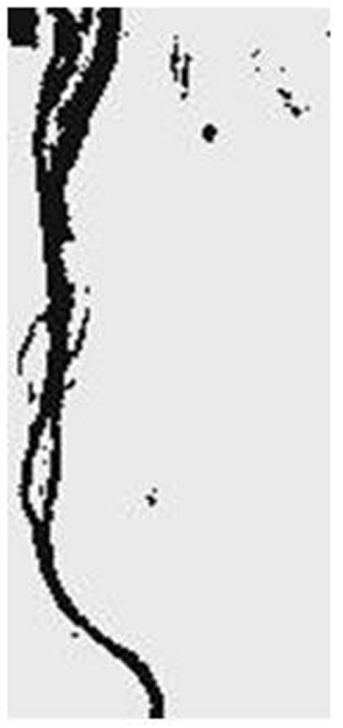

$26{ }^{\circ} \mathrm{C}$

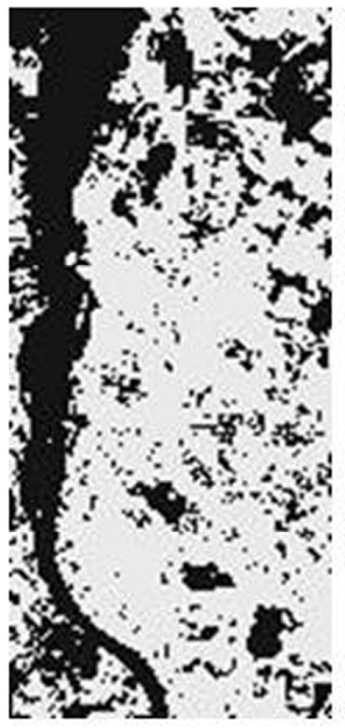

$33{ }^{\circ} \mathrm{C}$

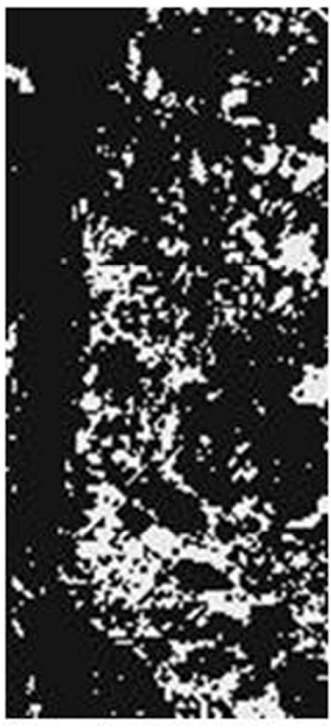

$37^{\circ} \mathrm{C}$

Figure 1. The role of the threshold temperature value by the examination of the central part of Budapest. The dark zones are colder, while the light zones are warmer than the given threshold temperature. (shot on $4^{\text {th }}$ May 2002) 
The areas warmer than this temperature value are brighter, while the areas colder than this value are darker (Fig. 1), this way it becomes possible to measure the temperature distribution in correlation with the land cover.

By using the temperature threshold values the hot and cold spots can be accurately identified in the city, consequently the anomalies become simply detectable and their size and rate can be measured exactly, furthermore in certain cases the isotherms clearly indicate the differences resulting from the various land uses and land covers.

The other method of processing the satellite images is the examination of the so called thermal cross sections. In this case it is the temperature distribution along a path which is measured (on a graph). Since the spatial resolution of the satellite images is $90 \mathrm{~m}$, this line is a $90 \mathrm{~m}$ wide band in practise. Furthermore by examining three similar neighbouring bands it becomes possible to depict and analyse graphically a $270 \mathrm{~m}$ wide band (Fig. 2).

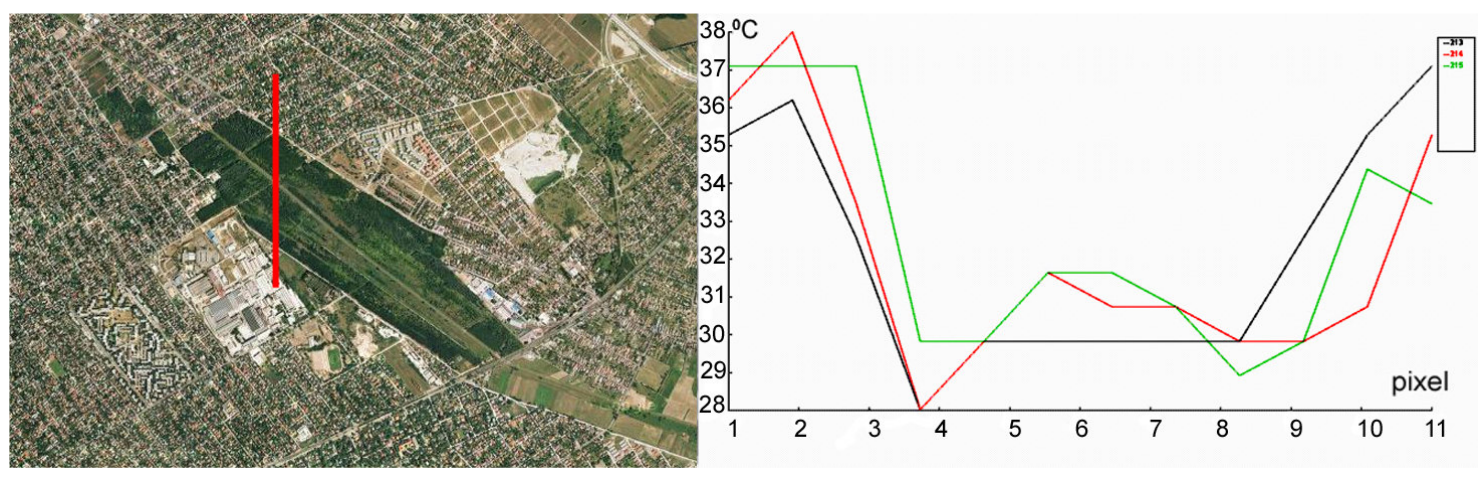

Figure 2. The so called thermal cross sections and their lines of recording on the map. Each line represents a pixel sequence of the thermal infrared satellite image. The examined area is a young poplar forest on the banks of the Szilas Creek in the $16^{\text {th }}$ District of Budapest.

(shot on 6 May 2008)

Through the two above mentioned methods cross sections with vertical and horizontal section planes were set on the urban heat island, which can be displayed as an inflected surface in the 3 dimensional spaces (the temperature values indicated in the $3^{\text {rd }}$ dimension above the 2 dimensional maps). These planes enable the accurate and comprehensible illustration of the phenomenon, and on the other hand they enable the achieving of not only qualitative but also the quantitative results.

It is very important to note that these are only case studies in the present work, opposite the thesis of Dezsö (2009) for example, in which the entire urban heat island of Budapest was examined on a daily basis for a several years long period based on the MODIS satellite image database (NASA, 1999). However, the measurements taken in different years but under similar macroclimatic and seasonal conditions ( $4^{\text {th }}$ May 2002 and $6^{\text {th }}$ May 2008) show very close similarities. This was in a way predictable, seeing the daily average temperature values and weather conditions of these days provided by the Hungarian Meteorological Service. The data show that these days were bright, clear and unclouded (anticyclonic conditions). Particularly this macroclimatic similarity made it possible to detect the anomalies in the structure of the urban heat island unequivocally caused by the change of the land use.

There is a very interesting possibility to increase the spatial resolution of these images (Jung et al., 2007). Its base is the fact that the NDVI indices highly correlate with the temperature values in some certain regions. As it is well known the NDVI 
index is derived from visible near infrared (VNIR) and short wave infrared (SWIR) radiation. The spatial resolution ability of these spectral bands is far better $(30 \mathrm{~m}$ and $15 \mathrm{~m}$ ) than that of the thermal infrared band $(90 \mathrm{~m})$. On this way a $30 \mathrm{~m}$ spatial resolution can be achieved, but only in areas covered by vegetation. Because of the urban fabric of Budapest is very complex and detailed, moreover huge parts of the city are biologically absolutely inactive, it is not worth to deal with this method, because it could be used only very limitedly.

On the whole, even though only case studies were analysed, still the fairly good spatial resolution ( $90 \mathrm{~m}$ as against the $1 \mathrm{~km}$ spatial resolution of the MODIS images), furthermore the mindful selection of the case studies and their deliberate comparison provide a good opportunity to examine the effects of the different land use forms and land cover types on the urban heat island.

\section{Results}

The results of the examination can be summarized as follows: the correlation between the urban heat island and the different land use form and land cover types is unequivocally proven. The examination also proved the significant role of the various albedo values in the development of the urban heat island. In the following the land cover types and surface materials with the most significant impact and their effect on the urban energy balance will be introduced according to the examinations.

\section{Water bodies}

Water bodies possess the most efficient urban heat island reducing effect in the summer period. The larger the water surface, the greater the impact; however, these are not proportionally related, since even relatively small water bodies (e.g. the lake in the Orczy Garden) have a significant temperature-reducing ability. The size of the Orczy Garden is about one hectar and considering the spatial resolution $(90 \mathrm{~m})$ of the satellite images and the fact that this small lake appears significantly on all spring and summer pictures it can be declared that the cooling effect of even such small water bodies are unequivocally remarkable. The rate of this cooling effect depends on many factors, however, it can be generally stated that water surfaces can reduce the temperature of their surroundings by even $10^{\circ} \mathrm{C}$ or more. At the same time water bodies appear as the warmest surfaces on the winter images (except for certain hot spots), thus, they are capable of moderating the local climate even in the winter period, which is very advantageous in the aspect of the liveability of the cities.

It is very interesting that in the case of the River Danube, which is the greatest water body of the city, the bridges above the river also appear on the satellite image (as warm pixels), even though their average width is only about $40 \mathrm{~m}$, while the spatial resolution of the images is $90 \mathrm{~m}$. The reason for this is probably that the temperature of the paved surface of the bridges is so much warmer than that of the water surface that they can influence the average temperature value of the given pixel even if they cover only a part of its area. Unfortunately these temperature values are a random average of the temperature of the water body and the surface of the bridge. Consequently only qualitative analysis is possible in these cases, however, it is interesting to see in Fig. 1 that at $19^{\circ} \mathrm{C}$ the bridges over the Danube all clearly appear, even though this is theoretically impossible. 


\section{Tree stands with closed canopy layers}

The next very important land cover type consists of forests, park forests, parks and other tree stands. In this case it can be declared that the urban heat island reducing effect of this land cover type is very significant both in the summer and in the winter period. The rate of this effect depends on several more factors than in the previous case. The plant species and age of the tree stands, the level of the subsoil water are all highly important. Furthermore the same abiotic factors impacting on the entire urban heat island itself play a significant role in the case of tree stands as well. All in all it can be declared that a multilevel tree stand with a closed canopy layer, consisting of well evaporating tree species with a sufficient water supply (a relatively high level of subsoil water or irrigation in the dry periods) can reduce the temperature even by approx $5-6^{\circ} \mathrm{C}$.

The role of the evaporation and photosynthesis (which transforms a significant part of the incoming radiation into chemical and not heat energy) is extremely important when examining the effect mechanisms. The effect was anticipated, according to the study, which showed the correlation between the biological activity and land surface temperature (Gábor and Jombach, 2009). Furthermore the shading effect of the vegetation must also be mentioned. To exactly understand the role of shading, it is necessary to examine the intensively maintained (thus intensively evaporating and photosynthesising) grassy surfaces. The examination of these areas show that their urban heat island reducing ability is approx. only $2-3^{\circ} \mathrm{C}$. Considering furthermore the wide repertoire of shading tools and double facades of the contemporary architecture, which are used for reducing the warming up of these buildings in the summer period, it can be said that simply the shading effect of the trees (without even considering their metabolism) is a very significant urban heat island reducing factor on its own (Olah, 2010b).

\section{Pavements}

It is necessary to highlight pavements among the urban land cover types strengthening the urban heat island. These are typically artificial (mostly concrete) or natural stones, furthermore concrete and asphalt surfaces. The majority of roof cover materials also belong to this category, e.g. ceramic tegula covering, bituminous flat roof pavements. The common feature of these materials is that their specific heat is relatively low, which means that they warm up very fast, furthermore the rainwater flows off from these surfaces in almost $100 \%$.

In the aspect of the heat balance the above facts together mean that these pavements are in many orders of magnitude poorer than the natural covers. Depending on the colour of the given artificial paving the warming effect can be $10^{\circ} \mathrm{C}$ or even more - the darker the pavement, the more it warms up, namely the bituminous flat roof cover and the asphalt pavement are the worst (Olah et al., 2010).

\section{Glass and metal covered buildings}

Glass and metal covered buildings need to be mentioned separately. These are typically huge institutional or commercial buildings, e.g. the new Coliseum (which is totally covered by metal) or large shopping centres (e.g. Arena Plaza), which usually have huge glass transom-windows (Fig. 3). 
These buildings have practically become the hottest spots of the entire city immediately after their completion (Fig. 4), taking over the leading position from the industrial territories, e.g. railway stations, factories, power plants (Olah, 2010a).

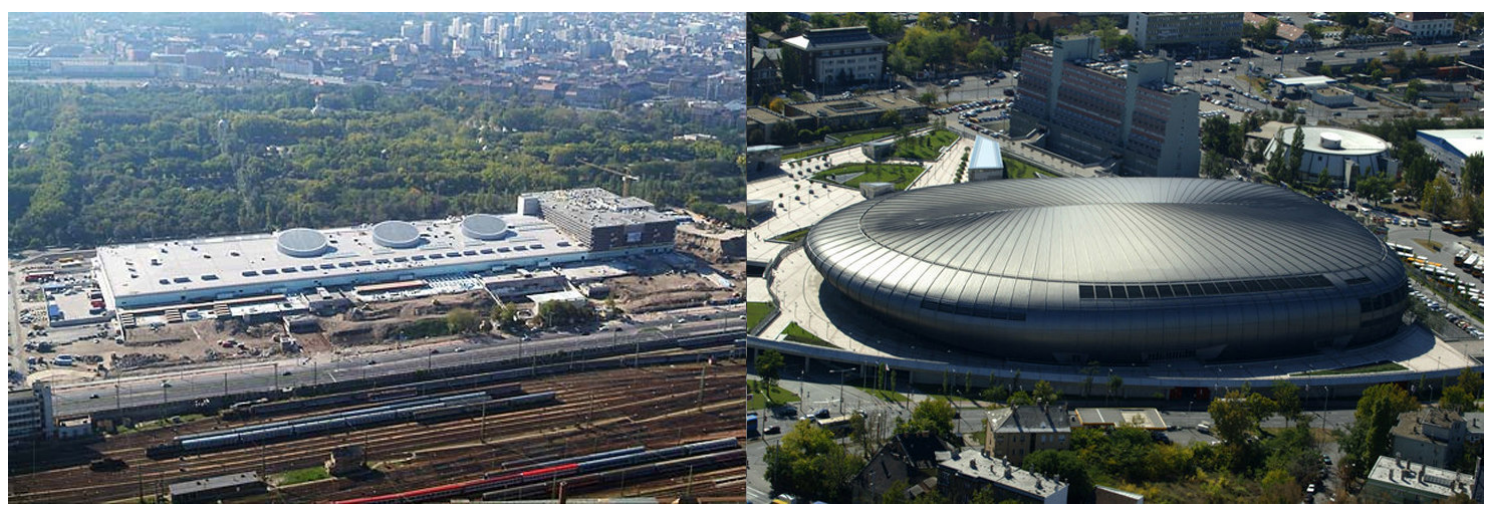

Figure 3. The new buildings: Arena Plaza and the Coliseum, the hottest points of the city.
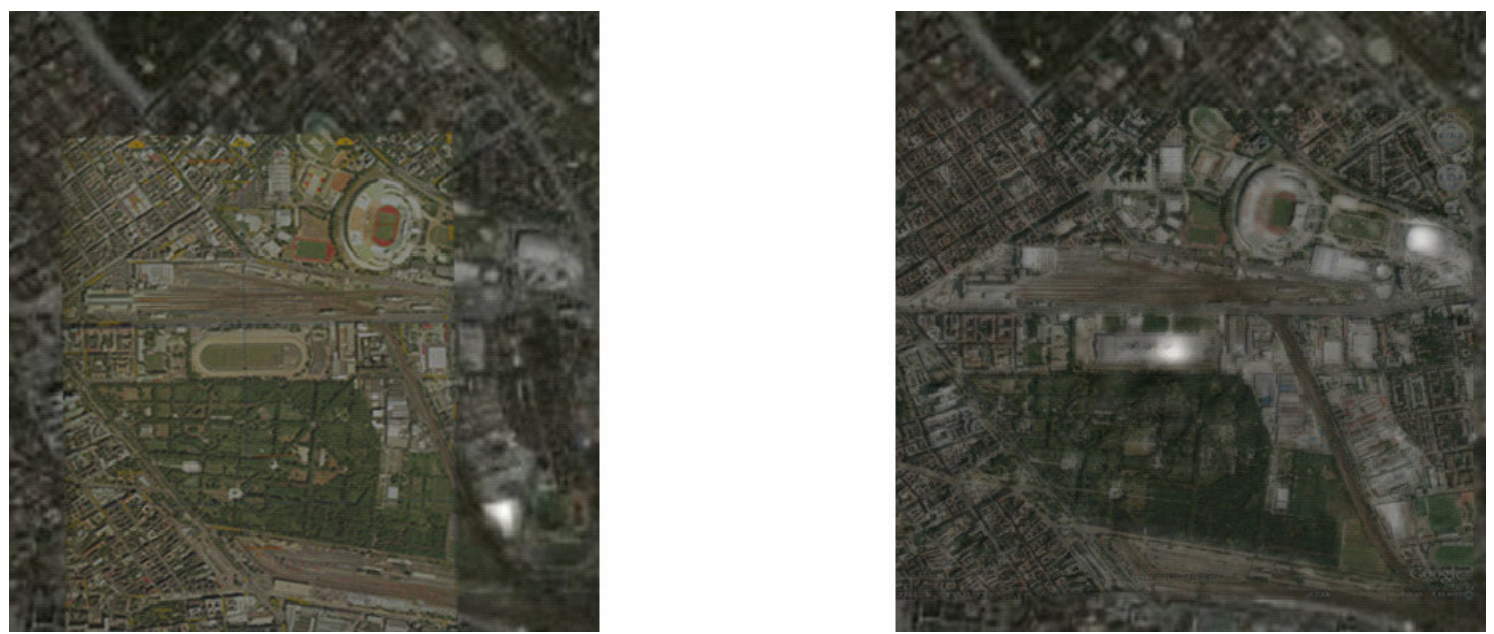

Figure 4. The effects of the new buildings: new hot points and absolutely new thermal distribution appear on the image shot on $6^{\text {th }}$ May 2008 (right) unlike the previous image shot on $4^{\text {th }}$ May 2002 (left)

\section{Different built-up types}

The qualitative analysis of the $6^{\text {th }}$ district of Budapest based on the image sequences featuring the threshold temperatures (Fig. 1) confirms the connection between the urban structure and the sky view factor (SVF), and the structure of the urban heat island, pointed out in the thesis of Gál (2009). Essentially, the urban land use forms and the surface temperatures of the examined area are the followings: those urban blocks, which fall eastwards from Bajza Street are significantly cooler than those, which fall westwards (towards the city centre) from this line (Fig. 5). This street appears to be a significant borderline also in the urban fabric, for on the western side there is a continouosly built-in row of buildings, while detached standing buildings (villas with gardens) can be found on the eastern side. In the case of continous rows of buildings the sky view factor (SVF) is much smaller in the first place than in the case of any other built-up types. In the current case this is the only real difference between these two 
urban areas, as all other features (usage intensity, number of building levels) the differences are only minor.

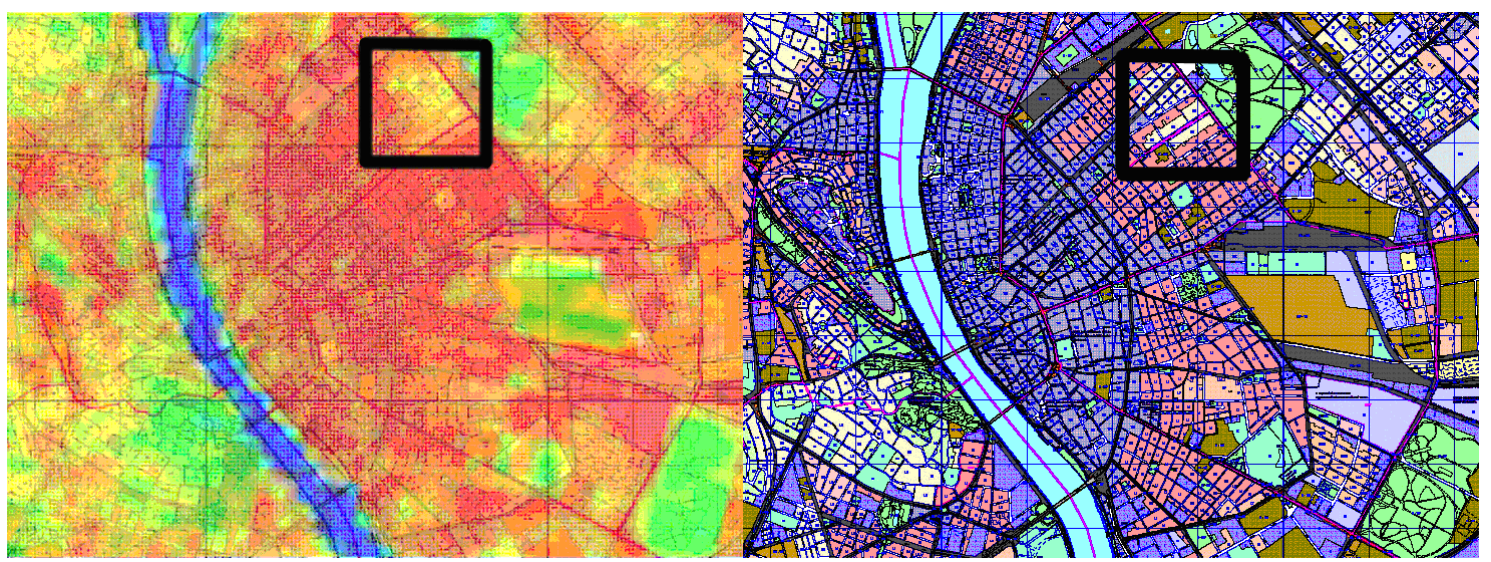

Figure 5. The role of the different built-up types: next to the City Park (towards the city centre) can be found a small cooler area represented by yellow color on the left infrared image, which can be exactly coupled with the detached built-up type area represented on the regulation plan (right). The infrared image was shot on $6^{\text {th }}$ July 2001.

\section{Summary of the results}

By summarizing the results we came to the conclusion that the factor predominantly responsible for the urban heat island is the albedo of a given area. In the case of artificial surfaces this is truly the most significant factor; however, in the case of natural surfaces other kinds of effects appear as well, e.g. the metabolism of the vegetation, biological activity and evaporation (Olah, 2011). The increase of both the biological activity and the evaporation causes the decrease of the temperature in the given area. It is very important to mention the water surface separately, which is basically considered as a natural surface; however, in this case it is unnecessary to calculate with such complex effects like plant metabolism. The primary aspect of the examining of the water bodies is its vaporizing ability, but its extremely high specific heat is also very important (if not even more important), as it enables the water bodies to very effectively decrease the daily temperature fluctuation.

\section{Discussion}

Discussion is relatively difficult in this case, as the aim is creating specified directives and guidelines for urban planning, for open space design and architectural design based on the results and particularly the conclusions of detailed urban meteorological examinations.

Nevertheless it must be declared that the results of this study are in accordance with the results of the professional literature and mostly certify and specifies the anticipations. The most important point is that the phenomenon of the cool island generated by large urban green areas, parks (called park cool island PCI) was unequivocally detected during this research as well, which is fully in accordance with the results of Szegedi and Gyarmati (2009). Moreover, thanks to the good spatial resolution of the utilized satellite images it was possible to make some statements about the structure of the given green area from the aspect of their urban heat island 
modifying ability. As against the anticipation, in certain special cases the spatial resolution of the applied satellite images enabled the possibility of a more accurate analysis than on the level of urban blocks. However, occasionally this more accurate analysis could only be a qualitative measuring, due to the strong limits set by the spatial resolution.

The most important result of this research is that it became possible to rank the different types of land covers in the aspect of the urban heat island. The consequences of this fact are particularly promising, since they provide the opportunity of a kind of feedback, namely the conscious influencing of the urban climate with the tools of urban planning, open space design and architecture.

The unequivocal detection of the park cool island (PCI) in Hungarian setlements (Szegedi and Gyarmati, 2009) provides the opportunity of a feedback, for the establishing of an urban park in a city is unequivocally a good example of urban planning and development because this way the urban climate can be consciously formed in a positive direction.

In point of the energy balance of settlements the role of the water bodies is extremely important, on the one hand as huge vapourizing surfaces, and on the other hand as huge heat reservoirs, which can very effectively balance the urban climatic conditions with a special regard to the daily temperature fluctuation. This fact is evident on a larger scale for everyone, but the detailed survey has proved the positive effects of relatively small water bodies as well.

The final conclusion of this study is that we got detailed data about the different urban heat island generating effects of the different urban surfaces. Moreover it was also proven that huge commercial buildings eventuates directly enormous heat impact on their environment. On the strength of this research the urban planning, the open space design and even the (building) architecture can have such new priorities which can eventuate the minimizing and preventing the development of the urban heat island phenomenon both locally and on the scale of the whole city. We have the opportunity and the tools of consciously influencing the urban climate in a positive direction, mainly by creating urban tree stands and green surfaces, furthermore by creating water bodies in greater size, number and density with the help of creating more environment conscious regulation plans and rules.

Acknowledgements. This paper was supported by the TÁMOP-4.2.1/B-09/01/KMR-2010-0005 project.

\section{REFERENCES}

[1] Bartholy, J., Pongrácz, R., Gelybó, Gy. (2007): Regional climate change expected in Hungary for 2071-2100. - Applied Ecology and Environmental Research 5(1): 1-17.

[2] Bartholy, J., Pongrácz R., Gelybó, Gy. (2009): Climate signals of the North Atlantic oscillation detected in the Carpathian basin - Applied Ecology and Environmental Research 7(3): 229-240.

[3] Dezső, Zs. (2009): A magyarországi és közép-európai nagyvárosokban kialakuló városi hősziget vizsgálata finom felbontású müholdképek alapján. - Thesis for $\mathrm{PhD}$ doctor's degree, ELTE, Budapest.

[4] Dobi, I., Mika J., Oláh, A.B., Lelovics E., Dezső, Zs., Pongrácz, R., Bartholy, J. (2009): Cold and hot events in urban environment. - In: ICUC-7, Int. Conf. on Urban Climate, Yokohama, Japan. 
[5] Gábor, P., Jombach, S. (2009): The relation between the biological activity and the land surface temperature in Budapest - Applied Ecology and Environmental Research 7(3): 241-251.

[6] Gál, T. (2009): The calculation of the parameters describing the complex urban geometry and application for urban climate investigation. - Thesis for $\mathrm{PhD}$ doctor's degree, University of Szeged.

[7] Howard, L. (1818): The climate of London, deduced from Meteorological observations, made at different places in the neighbourhood of the metropolis, 2 vol., London.

[8] Jung, A., Tökei, L., Kardeván, P. (2007): Application of airborne hyperspectral and thermal images to analyse urban microclimate - Applied Ecology and Environmental Research 5(1): 165-175.

[9] Lee, H.-Y. (1993): An application of NOAA AVHRR thermal data to the study or urban heat islands. - Atmospheric Environment 27B: 1-13.

[10] Mika, J. (1999): A városi hősziget-hatás és a globális klímaváltozás kapcsolatáról. Éghajlati és Agrometeorológiai Tanulmányok 6: 69-80.

[11] Moreno-garcia, M.C. (1994): Intensity and form of the urban heat island in Barcelona. International Journal of Climatology 14(6): 705-710.

[12] NASA (1999): Science writers' guide to Terra. - NASA Earth Observing System Project Science Office, Greenbelt, MD

[13] Oke, T.R. (1973): City size and the urban heat island. - Atmos. Environ. 7: 769-779.

[14] Oke, T.R., Spronken-Smith, R.A., JaHuregui, E., Grimmond, C.S.B. (1999): The energy balance of central Mexico City during the dry season. - Atmospheric Environment 33: 3919-3930.

[15] Olah, A.B. (2010a): Detected effect of a newly constructed huge building on the heat balance of its surroundings. - In: $9^{\text {th }}$ International Conference on Application of Natural-, Technological and-, Economical Sciences, Szombathely, Hungary.

[16] Olah, A.B. (2010b): The effects of different vegetation types on the local climate. - In: Machar, I., Kovár, P. (eds) Book of abstracts of International Conference in Landscape Ecology, Brno, Czech Republic.

[17] Olah, A.B., Dobi, I., Mika, J., Lelovics, E., Dezső, Zs., Pongrácz, R., Bartholy, J. (2010): The correlation between the urban heat island and the different land use types. - In: Fábos, J.Gy. et al.(eds) Proceedings of Fábos Conference on Landscape and Greenway Planning, Budapest, Hungary.

[18] Olah, A.B. (2011): The prevailing of the ecological and sustainable requirements and the effects of the global climate change in the planning directives of the urban green areas and open spaces. - In: VIIth Conference on Environmental Studies in the Carpathian Basin, Kolozsvár, Rumania.

[19] Pongrácz, R., Bartholy, J., Dezső, Zs. (2007): Thermal structure of large central European cities using remotely sensed data - In: Střelcová, K., Škvarenina, J., Blaženec, M. (eds.): "Bioclimatology and natural hazards" International Scientific Conference, Pol'ana nad Detvou, Slovakia, September 17 - 20, 2007.

[20] Probáld F. (1974): Budapest városklímája (The Urban Climate of Budapest). Akadémiai Kiadó, Budapest.

[21] Révész, A. (2008): Stochastic behaviour of heat waves and temperature in Hungary Applied Ecology and Environmental Research 6(4): 85-100.

[22] Rosenfeld A.H, Romm, J.J., Akbari H., Lloyd A.C. (1997): Painting the town white and green. - MIT Technology Review 100: 52-59.

[23] Szegedi, S., Gyarmati, R. (2009): Impacts of Urban Green Spaces on the Spatial Structure of the Urban Heat Island in Debrecen and Different Sized Settlements in Its Neighbourhood. - Acta Climatologica et Chorologica Universitatis Szegediensis 42-43: 151-158.

[24] Unger, J. (2009): A városi hősziget jelenség néhány aspektusa (Some aspects of the urban heat island phenomenon). - Thesis for the MTA doctor's degree. 